\title{
Numerical and Experimental Validation of Gas Metal Arc Welding on AISI 441 Ferritic Stainless Steel Through Mechanical and Microstructural Analysis
}

SERAFINO CARUSO ( $\nabla$ serafino.caruso@unical.it )

University of Calabria https://orcid.org/0000-0003-4090-6133

DOMENICO UMBRELLO

University of Calabria

\section{Research Article}

Keywords: Finite element modeling, Grain size, Hardness, Residual stress, Heat affected zone, Gas metal arc welding.

Posted Date: January 6th, 2022

DOI: https://doi.org/10.21203/rs.3.rs-1187414/v1

License: (c) (i) This work is licensed under a Creative Commons Attribution 4.0 International License.

Read Full License 


\title{
NUMERICAL AND EXPERIMENTAL VALIDATION OF GAS METAL ARC WELDING ON AISI 441 FERRITIC STAINLESS STEEL THROUGH MECHANICAL AND MICROSTRUCTURAL ANALYSIS
}

\author{
Serafino Caruso ${ }^{1 *}$, Domenico Umbrello ${ }^{1}$ \\ 1 Department of Mechanical, Energy and Management Engineering, University of Calabria, \\ Rende, CS 87036, Italy. ORCID: 0000-0003-4090-6133 (S. Caruso), 0000-0002-4211-6322 (D. \\ Umbrello)
}

Corresponding author.

E-mail address: serafino.caruso@unical.it (S. Caruso)

\section{ABSTRACT}

Residual stresses and strains, distortion, heat affected zone (HAZ), grain size changes and hardness variation during gas metal arc welding (GMAW), are fundamental aspects to study and control during welding processes. For this reason, numerical simulations of the welding processes represent the more frequently used tool to better analyse the several aspects characterizing this joining process with the aim to reduce lead time and production costs. In the present study an uncoupled 3D thermo-mechanical analysis was carried out by two commercial finite element method (FEM) software to model an experimental single bead GMAW of AISI 441 at different process set-up. The experimental HAZ and measured temperatures were used to calibrate the heat source of both the used numerical codes, then a validation procedure was done to test the robustness of the two developed analytical procedures. One software was used to predict the residual stresses and strains and the distortions of the welded components, while in the second software a user routine was implemented, including a physical based model and the Hall-Petch $(H-P)$ equation, to predict grain size change and hardness evolution respectively. The results demonstrate that the predicted mechanical and microstructural aspects agree with those experimentally found showing the reliability of the two codes in predicting the thermal phenomena characterizing the HAZ during the analysed welding process.

Keywords: Finite element modeling, Grain size, Hardness, Residual stress, Heat affected zone, Gas metal arc welding. 


\section{NOMENCLATURE}

$\mathrm{C}_{0} \quad$ numerical constant

CSM computational solid mechanic

D current grain size

$\mathrm{D}_{0} \quad$ initial grain size

FE finite element

FEM finite element method

GMAW gas metal arc welding

GTAW gas tungsten arc welding

HAZ heat affected zone

H-P Hall-Petch

HSFT heat source fitting tool

HV hardness Vickers

IRC infra-red camera

Q activation energy for grain growth

$\mathrm{R} \quad$ gas constant

SAW submerged arc welding

$\mathrm{T} \quad$ current temperature

UMW ultrasonic metal welding

a heat source parameter

b heat source parameter

$\mathrm{c}_{1} \quad$ heat source parameter

$\mathrm{c}_{2}$ heat source parameter

d average grain size

$\mathrm{k} \quad$ numerical constant

$\mathrm{k}_{0} \quad$ numerical constant

$\sigma_{\mathrm{y}} \quad$ yield strength

$\sigma_{0} \quad$ numerical constant

m numerical constant

$\mathrm{t}$ time

$\eta \quad$ heat source efficiency

\section{INTRODUCTION}

Among the several joining techniques, welding process has gained increasing importance in the industrial manufacture due to the possibility to get increasing volume production of components with good requisite of welding quality: less distortions, deeper penetration, reduced HAZ, etc [1, 2]. At the same time, consumption reducing and sustainability represent common objectives in the fight against climate change as well as indicator of any human activity [3-5]. For this reason, it is necessary to known and control the main process parameters influencing the welding zone and choose the right set, avoiding any trial (i.e. tools and machine cost, manpower, time, material, waste production and management), to get the component with the best performance. In this contest, developing predictive numerical models is the industrial and academic need to improve reliability, productivity and performant products and to have a better knowledge and control of the influence of the process parameters on the final properties of the components. It is important to highlight that the numerical modelling is one of the pillars characterizing the fourth industrial revolution (also known as Industry 4.0 (I4.0)) improving industrial processes in terms of flexibility, efficient production, cost reduction and sustainability [6, 7]. The synergy, between the trending concept of the I4.0 and the manufacturers challenge in getting an excellent welded joint, induce to have an accurate awareness of the phenomena characterizing the joining procedure, and its evolution during the process, with the aim to achieve the desired and reliable outputs. This scenario proves the application of the numerical modelling as a valid tool for welding investigation and analysis. Focusing on this concept, several researches were proposed, demonstrating the increasing interest in modelling the thermo-mechanical aspects of the welding process and their influence on the joined parts: deformation, residual stresses, microstructural changes, etc [8-10].

S. Dancette et al. [11] developed a finite element (FE) model with the aim to investigate the deformation and the fracture behaviour of Usibor1500/DP600 dissimilar resistance spot welds. 
It was compared with 24 experiments at changing weld size, sheet thickness and loading type leading to a better understanding of the several aspects influencing the weld behaviour. The good numerical results showed the advantages of the developed numerical model for the design of optimized heterogeneous assemblies with reduced weight in the automotive industry. B. Mayghani [12] implemented a friction stir welding process by a Eulerian based computational solid mechanic (CSM) model. Analysing the influence on the stress, process temperatures, equivalent plastic strain and material flow and comparing the proposed model with the conventional Coulomb friction model the author demonstrated the good agreement by comparison with experimental results and literature. A.K. Mondal et al. [13] proposed a new volumetric avocado shape heat source for welding processes. The shown model is an advanced version of the conventional ellipsoidal shape with non-symmetrical energy distribution and unequal axis length in the front and rear parts. The developed heat source model was validated by performing a FE based heat transfer analysis for both gas tungsten arc welding (GTAW) and submerged arc welding (SAW). The good agreement with corresponding experimental results showed the accuracy of the new heat source model and tis flexibility in analysing different fusion welding processes. H. Heyraud et al. [14] proposed a numerical two-scale approach, combining solid and shell finite elements, for non-local multiaxial equivalent stress at the weld toe and the weld root. The influence of the parameters of the new model on the stiffness behaviour was investigated for three welded structures and for different loading cases. The obtained results and the comparison with other models from literature validated the potential of the innovative approach for the fatigue design of large welded structures. N. Shen et al. [15] developed and validated, by comparison with experimental data, a series of FE models, by the commercial software ABAQUS/Explicit and SFTC DEFORM-3D ${ }^{\mathrm{TM}}$, able to simulate the multilayer ultrasonic metal welding (UMW), with a vibration frequency of $20 \mathrm{kHz}$ or higher, both for short welding duration (0.1-0.5 s) and long welding duration (1 s). The authors demonstrated the reliability of the proposed $3 \mathrm{D}$ FE models in simulating the several aspects characterizing the material response during UMW process and controlling the process during its evolution. The literature analysis shows as welding, with particular focus on the HAZ, needs a detailed study to have a comprehensive knowledge of the thermo-mechanical phenomena that occur during the process, since they have a significant influence on the mechanical response and quality of the component. Moreover, the recent literature [16-18] highlights as developing robust numerical models is still attracting a relevant interest both for industrial and academic research. For this reason, with the aim to give a contribution in this direction, in the present work an uncoupled 3D thermo-mechanical analysis, by the commercial software codes SYSWELD and SFTC DEFORM-3D ${ }^{\mathrm{TM}}$, was carried out to model experimental single beads GMAW of AISI 441. By combining the efficiency of the two software, the authors deeply investigated the welding process. Furthermore, two customized user sub-routines, to predict the grain growth and hardness variation, were developed and implemented in SFTC DEFORM$3 \mathrm{D}^{\mathrm{TM}}$. The procedure for the heat source definition and calibration is also reported, and a comparison between the numerical results and the corresponding experimental data was carried out to validate the models. The effectiveness of the proposed procedure to measure and control residual stresses and strains, distortions, grain size evolution and hardness change is shown.

\section{EXPERIMENTAL PROCEDURE}


AISI 441 ferritic stainless steel (Table 1) was joined by GMAW procedure by a fully automated torch movement. The welds were performed on two plates of $1.5 \mathrm{~mm}$ of thickness and $248 \mathrm{HV}_{0.01}$ of hardness, with the geometry and the clamping setup as reported in Fig. 1. The welding parameters were
220 A current, $11.9 \mathrm{~V}$ voltage, $800 \mathrm{~mm} / \mathrm{min}$ weld speed and $12.2 \mathrm{~m} / \mathrm{min}$ filler material speed deposition (AISI 307 with a diameter of $\phi=1 \mathrm{~mm}$, Table 2). Pure Argon with a flow rate of $151 / \mathrm{min}$ was used as shielding gas.

Table 1 Chemical composition of AISI 441

\begin{tabular}{cccccccccc}
\hline Elements & $\boldsymbol{C r}$ & $\boldsymbol{C}$ & $\boldsymbol{M n}$ & $\boldsymbol{S i}$ & $\boldsymbol{A l}$ & $\boldsymbol{T i}$ & $\boldsymbol{N b}$ & $\boldsymbol{M o}$ & $\boldsymbol{F e}$ \\
\hline Weight $\%$ & 17.83 & 0.01 & 0.24 & 0.60 & 0.006 & 0.13 & 0.55 & 0.01 & Balance \\
\hline
\end{tabular}

Table 2 Chemical composition of AISI 307

\begin{tabular}{cccccccccc}
\hline Elements & $\boldsymbol{C r}$ & $\boldsymbol{C}$ & $\boldsymbol{M n}$ & $\boldsymbol{S i}$ & $\boldsymbol{P}$ & $\boldsymbol{S}$ & $\boldsymbol{N i}$ & $\boldsymbol{M o}$ & $\boldsymbol{F e}$ \\
\hline Weight \% & 20.30 & 0.08 & 3.3 & 0.90 & 0.04 & 0.015 & 8.50 & 1.5 & Balance \\
\hline
\end{tabular}
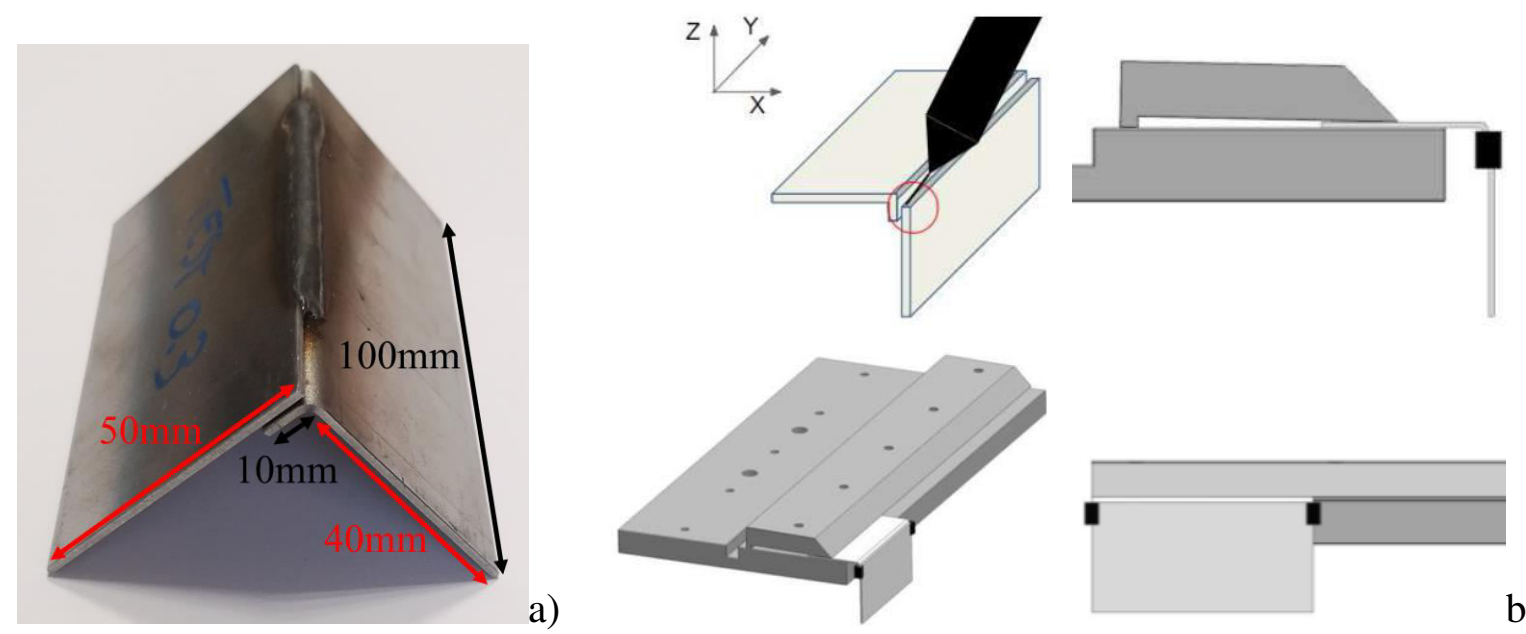

Fig. 1 Sample geometry a), clamping setup b)

Considering the coordinate system reported in Fig. $1 b$ the influence of three factors on the quality of the weld bead was experimentally considered: $D x$

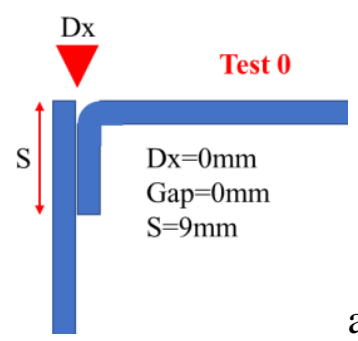

a)

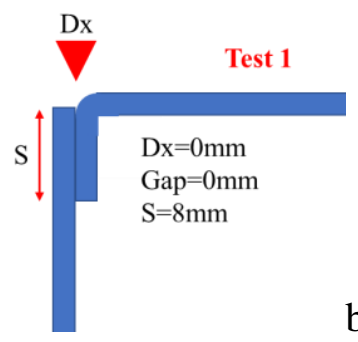

b) (torch position on x-axis), Gap (distance between the two plates) and $S$ (overlap between the two plates), Fig. 2a-h.
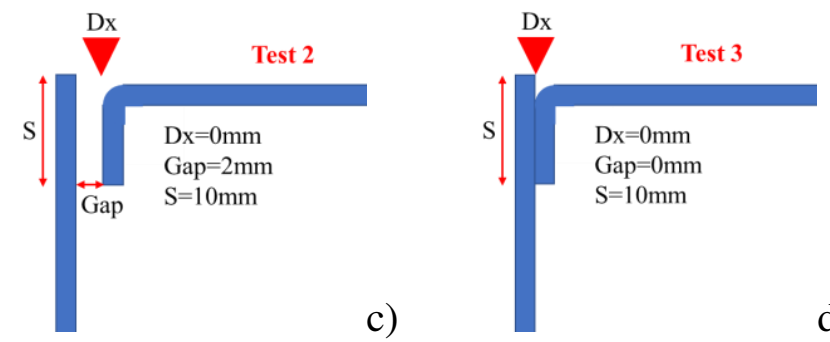

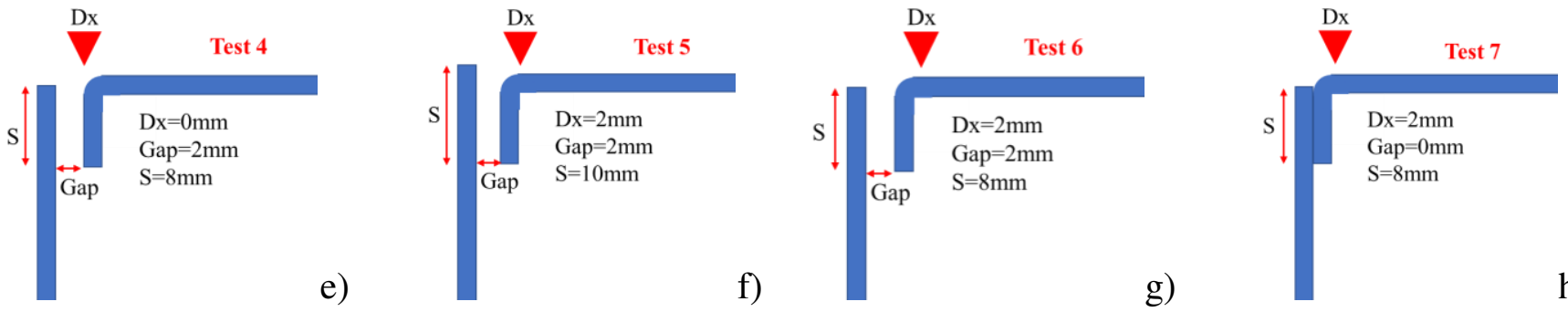

Fig. 2 Coordinate system a), welding configuration b-i)

Eight configurations were analysed (Fig. 2) with a repeatability of three, for a total of twenty-four tests. After welding, samples of $30 \mathrm{~mm}$ of length (ydirection, Fig. 2a) were mounted into a resin holder for the microstructural investigation. The metallographic preparation consisted of mechanical polishing and etching by the use of Keller's reagent
(92 $\mathrm{ml}$ of distilled water, $6 \mathrm{ml}$ of nitric acid, $2 \mathrm{ml}$ of hydrochloric acid and $2 \mathrm{ml}$ hydrofluoric acid). The cross sections of the welded components were analysed by an optical microscope to study the weld bead geometry, the HAZ extension and the grain size change, Fig. 3.

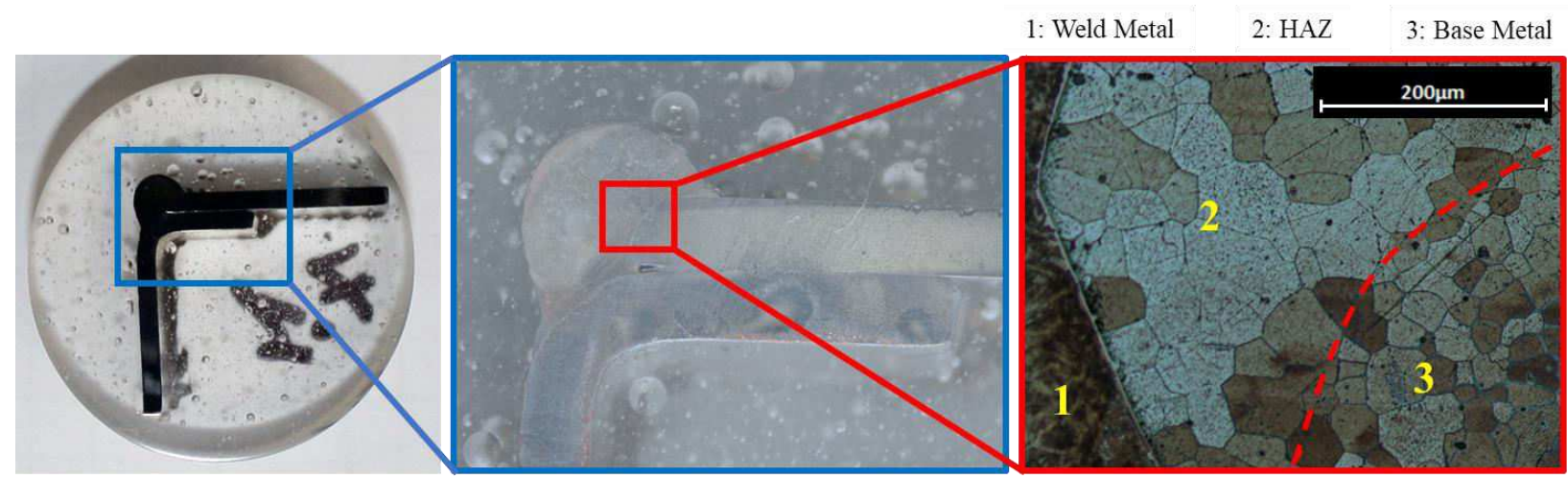

Fig. 3 Test 7: cross-section metallographic analysis

Considering the weld bead geometry, it was noticed that test 2, 4, 5 and 6 didn't reach a good quality requirement for welding (Fig. 4), showing as the investigated gap represents a critical aspect, for the examined process parameters, since it doesn't allow to correctly join the two plates.
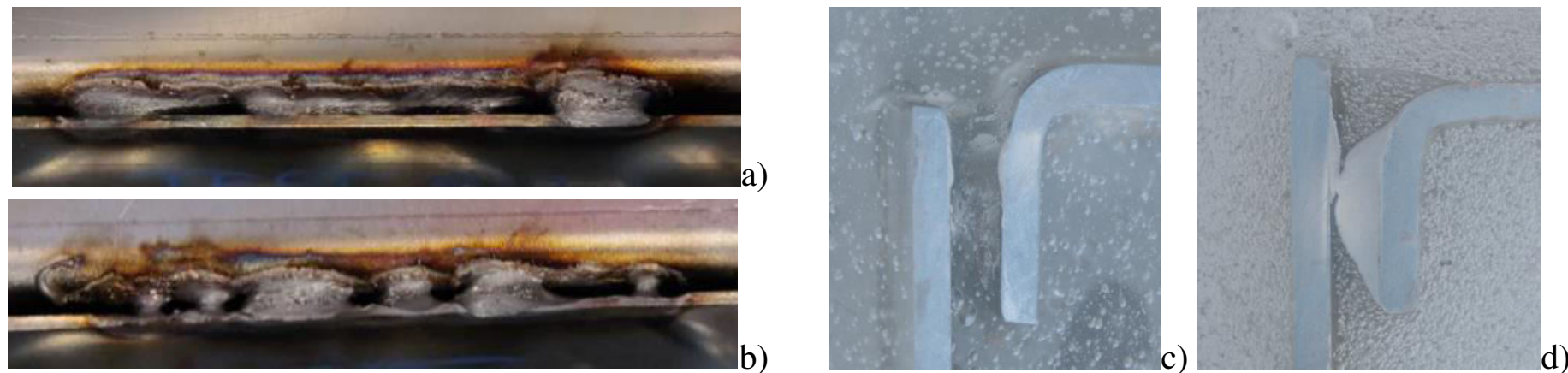

Fig. 4 Influence of the gap on welding quality: test 6 a), c) and test 5 b),d) 
Fig. 5 shows the grain size change between the base material and the HAZ. Fig. 5a represents the unaffected zone with an average grain size of $35 \mu \mathrm{m}$. Fig. $5 b$ and $5 c$ show the average grain size of the HAZ respectively for test $0(65 \mu \mathrm{m})$ and test $3(60$ $\mu \mathrm{m})$ both reporting a coarser grain due to the temperature increase that triggers the grain growth: an increase more than $70 \%$ was observed. In all the investigated samples the grain maintained an equiaxial shape, featuring a dominant coarse grained HAZ.
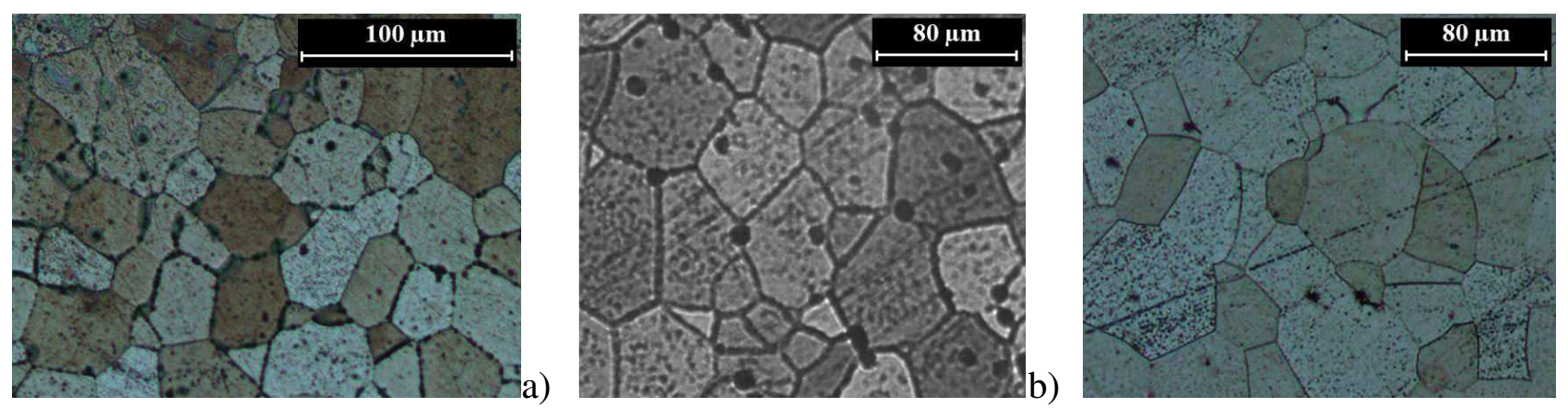

c)

Fig. 5 Cross section grain size: unaffected zone a), HAZ test 0 b), HAZ test 3 c)

The micro-hardness was measured by an indentation matrix of $22 \times 3$ points (Fig. 6a) showing a decreasing trend from base metal (unaffected zone) to HAZ (Fig. 6b and Fig. 6c). This result agrees with the analysed grain growth (Fig. 5) according to the Hall-Petch relation that considers the hardness evolution as an inverse function of the grain size (Eq. 1).

$$
H V=C_{0}+\frac{C_{1}}{\sqrt{d}}
$$

Where $C_{0}$ and $C_{1}$ are two material constants while $d$ represents the average grain size.
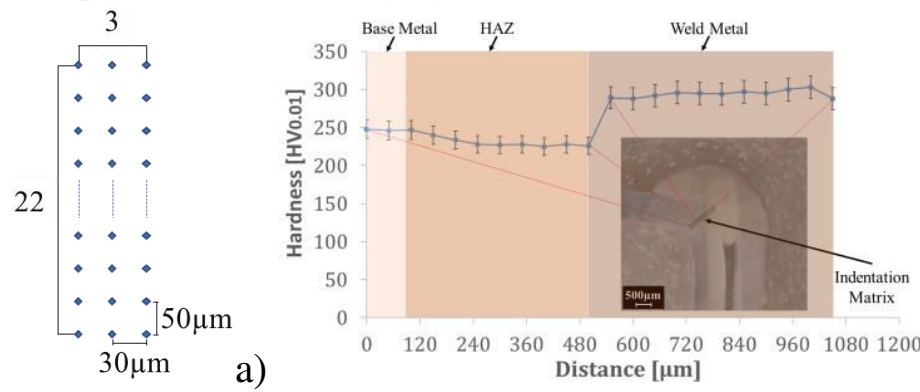

a)

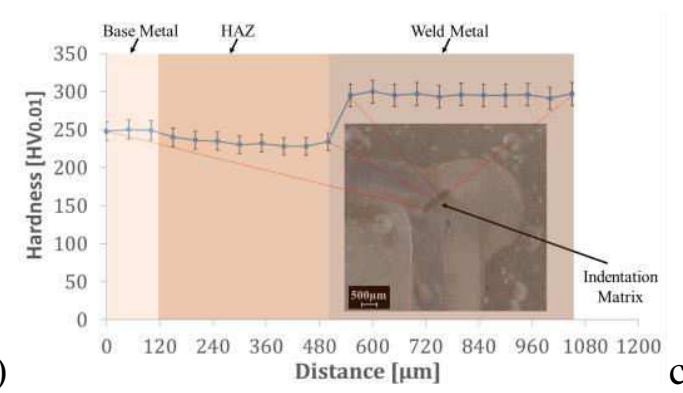

b)

In Fig. 7 the influence of the investigated factors $D x$ and $S$, on the welded samples, is shown. Figure $7 \mathrm{a}$ reports the HAZ extension of the four welded samples, determined by measuring and comparing both the grain growth and the hardness variation. Comparing test 1,0 and 3 , in which the factor $S$ (overlap between the two plates) is increased from 8 to $10 \mathrm{~mm}$, it is evident an HAZ reduction. Same behaviour is shown when comparing test 1 and 7 , in which the factor $D x$ (torch position on $\mathrm{x}$-axis) is shifted of $2 \mathrm{~mm}$.

Fig. 6 Hardness indentation matrix a), cross section hardness measurement test 0 b) and test 3 c) 
In both cases, moving the heat source away from the welding zone (i.e. contact line of the two plates) results in reduced process temperatures leading to a different HAZ length. According with the HAZ trend, the microstructure (i.e. grain size) shows an average grain size reduction with the increase of the factors $S$ and $D x$. Also, in this case, the lower reached temperatures lead to a decreasing tendency of the grain growth, Figure $7 \mathrm{~b}$. Related to the grain size evolution (Eq. 1), an opposite trend for the hardness variation is reported: coarser the grain size decreasing is the hardness.
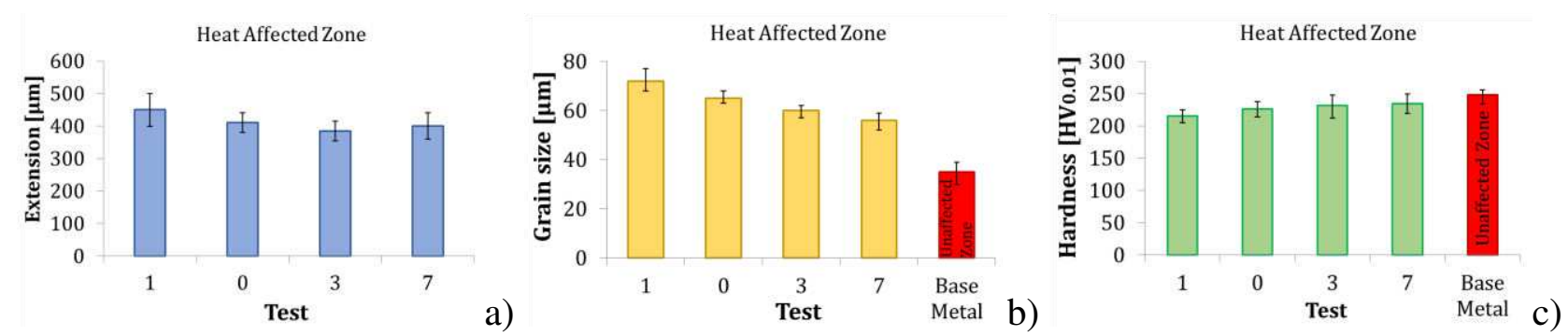

Fig. 7 Cross section: HAZ extension a), HAZ grain growth b), HAZ hardness change c)

The temperature history during the welding has been recorded by a FLIR A655sc Infra-Red Camera (IRC) able to capture and measure the temperature allowing to store data related to thermal field over the entire weld surface of the specimens under the visual zone. Among the IRC available configuration options, a range temperature acquisition of 100$650^{\circ} \mathrm{C}$ was set, leading to analyse the cooling phase of the process that, for its long duration, is considered the main significant as cause of residual stresses and strains and geometrical distortion.

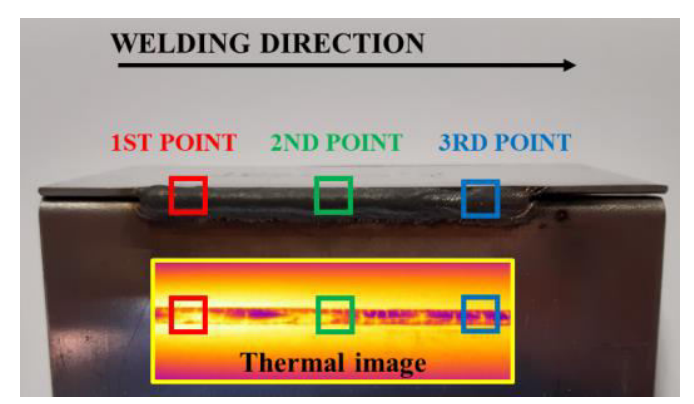

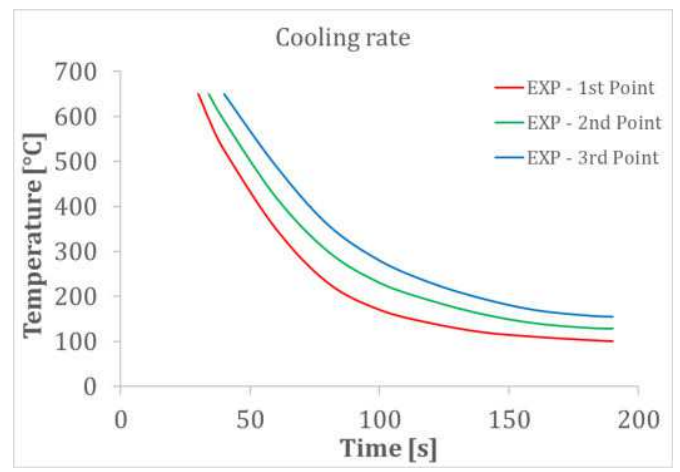

Fig. 8 Thermal tracking point positioning

From the stored thermal data, it was possible to analyse each sample by extracting the cooling temperature-trend from three points, respectively at the beginning, the centre and the end of the weld bead, Fig. 8. The above shown temperature analysis will enable to calibrate, by an iterative trial and error procedure, the parameters featuring the heat source model of both the investigated FE software. The same approach was used to set the temperature and the convection coefficient of the heat exchange windows implemented in the commercial software SFTC DEFORM-3D ${ }^{\mathrm{TM}}$ to model the welding heat source.

\section{NUMERICAL MODEL}


Considering the experimental results got by microscope and IRC, it was developed and calibrated the numerical model in the commercial code SYSWELD for the prediction of the residual stresses and strains and the distortions caused by the GMAW process. In particular, numerical modelling of the welding process by SYSWELD requires three main steps: material definition, geometry of the parts and
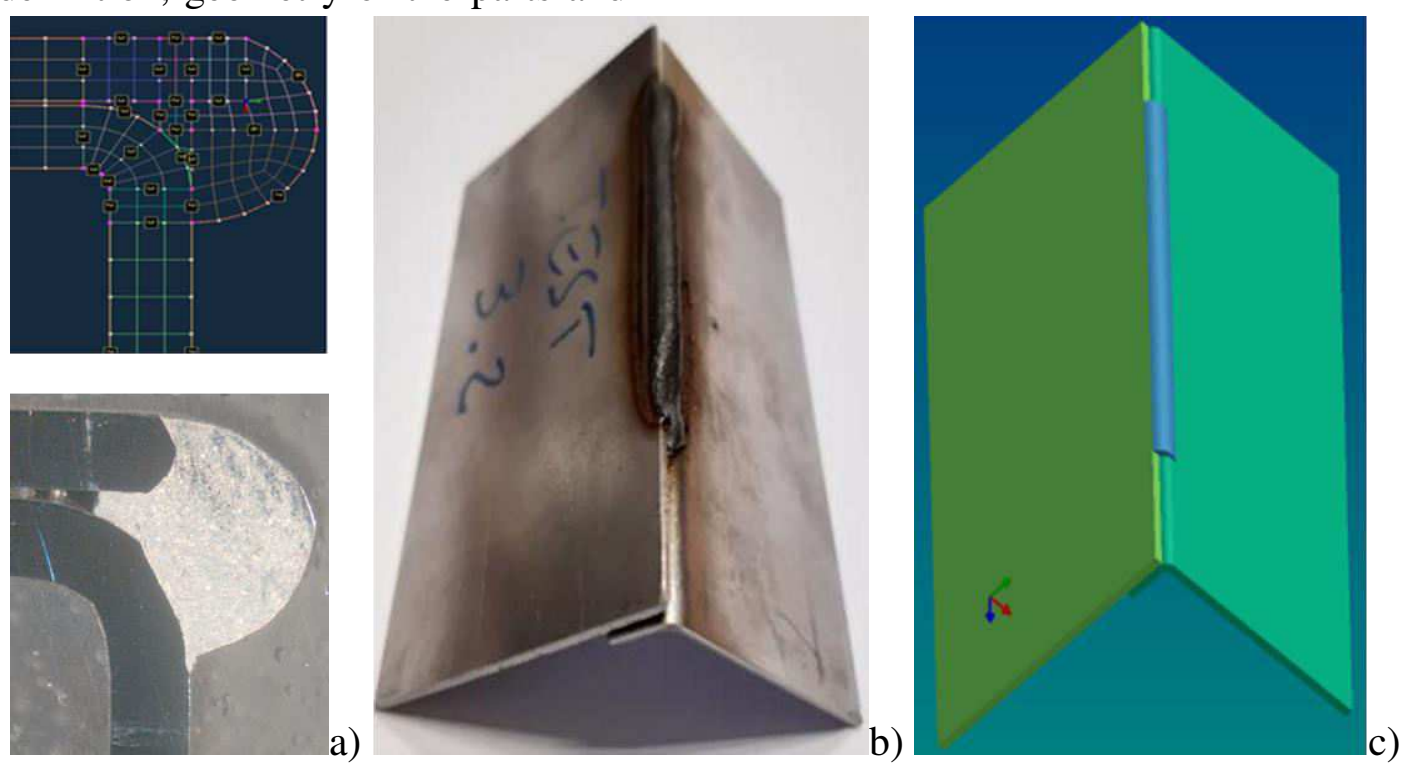

Fig. 9 Test 3: geometry numerical modelling by macrograph a), welded sample b), SYSWELD model c)

To simulate the GMAW, the volumetric heat flux distributions on the weld zone was represented by a three-dimensional Goldak's double-ellipsoid heat source model (Fig. 10), where $a, b, c_{1}$ and $c_{2}$ are the heat source fitting. Material properties were implemented by the material definition tool available in the software. The geometry of the three parts (two plates and weald bead) were modelled in SYSWELD by considering the initial measurements of the plates (Fig. 1) and the macrographs with particular focus on the weld bead geometry, Fig. 9.

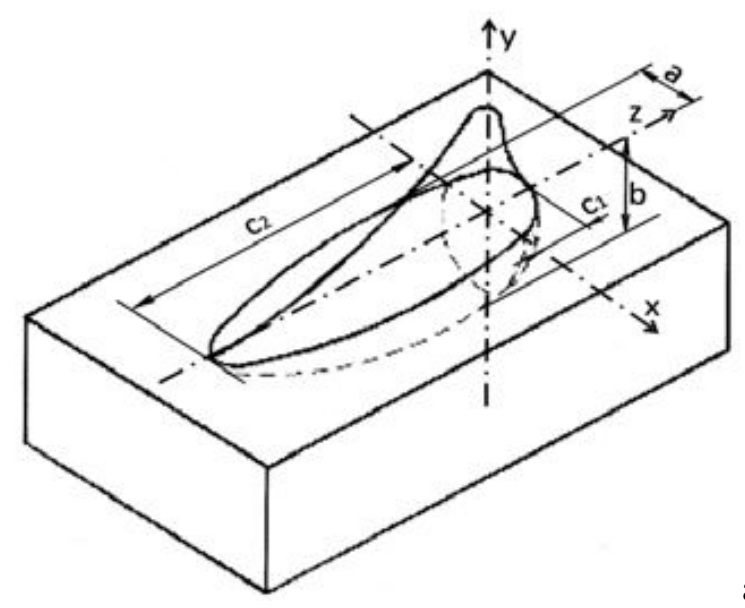

a)
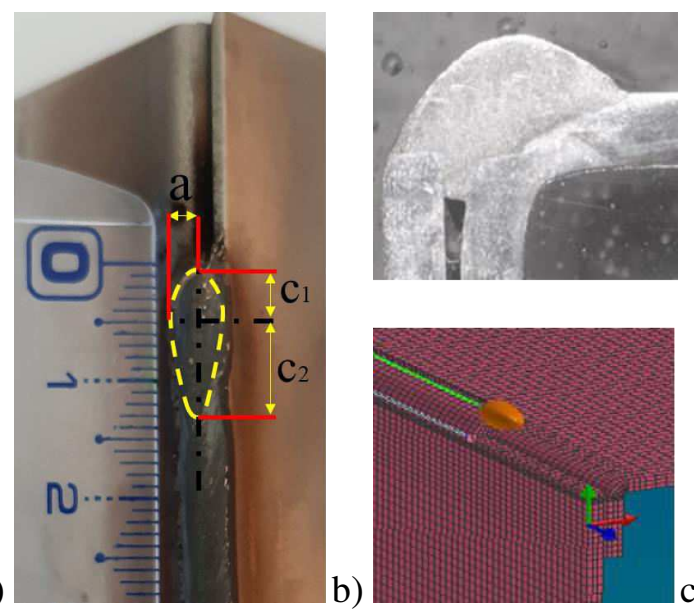

ellipsoidal heat source parameters (Fig. 10a), respectively the half width, the depth of penetration, the front length of molten pool and the rear length of molten pool.

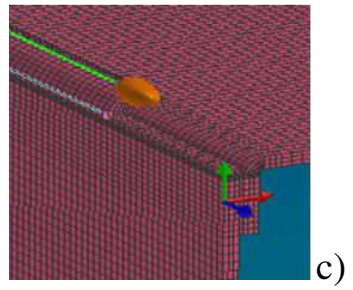

Fig. 10 Double-ellipsoid heat source model a), determination of the fusion zone parameters $a, c_{1}$ and $c_{2}$ 
b), test 1: macrograph and Goldak's heat source modelling c)

The heat source adjustment is based on the experimentally determined and measured values. In particular, it was necessary to define the parameters of the fusion zone $a, b, c_{1}, c_{2}$ and the efficiency of the heat transfer from source into material $\eta$. The heat source fitting tool (HSFT) is a useful option existing in SYSWELD, which enables to calibrate the parameters of the heat source to obtain more accurate simulation results. The user is able to calibrate the heat source shape and efficiency by a combination of two procedures: i.an iterative procedure of comparison between the modelled fusion zone and HAZ with the macrograph of the analysed sample (Fig. 11a and b) and ii.a cooling rate comparison between the data stored by IRC with those predicted by SYSWELD (Fig. 11c). The accuracy of the thermo-mechanical analysis is related to the correctness of the heat source shape and size (Fig. 10c) and of the material properties data. Fig. 11d shows the comparison between the predicted HAZ and the macrograph at the end of the calibration phase. A good agreement was found between the numerical results and the corresponding experimental outcomes with a maximum difference of about $11 \%$ for test 1 .
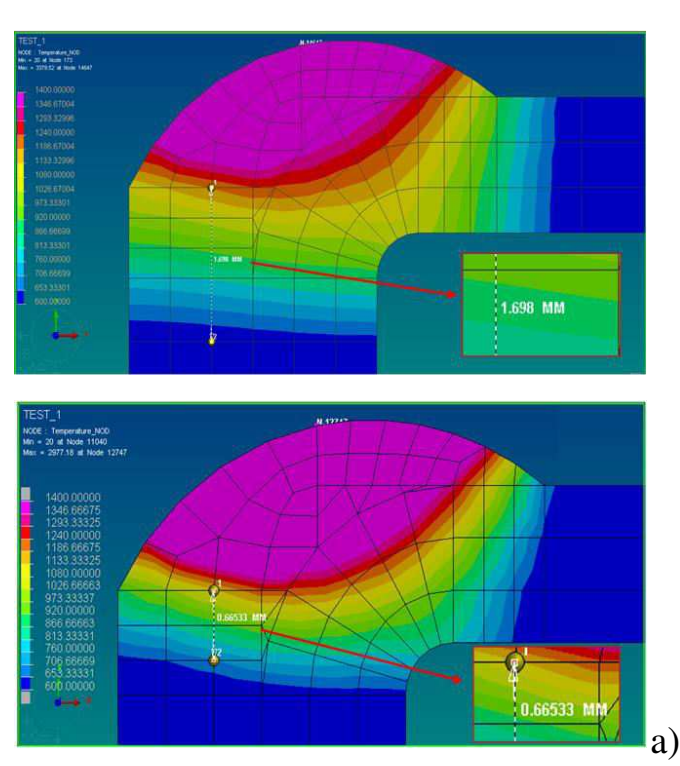
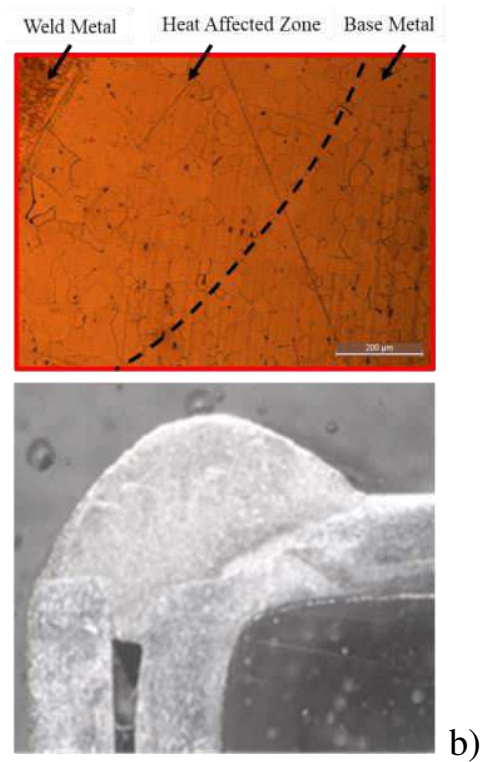
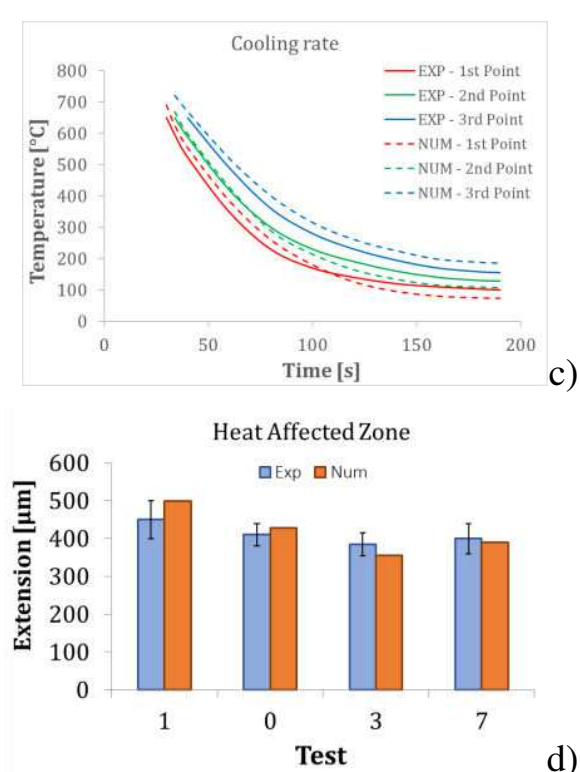

Fig. 11 Test 1: calibrating heat source - predicted fusion zone and HAZ a), experimental macrograph b), comparison between numerical and experimental cooling rate c) - and numerical analysis of the HAZ d)

Moreover, the experimentally registered temperatures by IRC were compared with the numerical thermal histories: the numerically predicted cooling rate agrees with the IRC data, Fig. $11 \mathrm{c}$.

The good results obtained between predicted and measured data (i.e. fusion zone, HAZ and cooling rate, Fig. 11) confirm i.the correctness of the heat source shape, size and efficiency ii.the accuracy of the material properties data and iii.the robustness of the developed numerical model in predicting residual stresses and strains and distortions. 

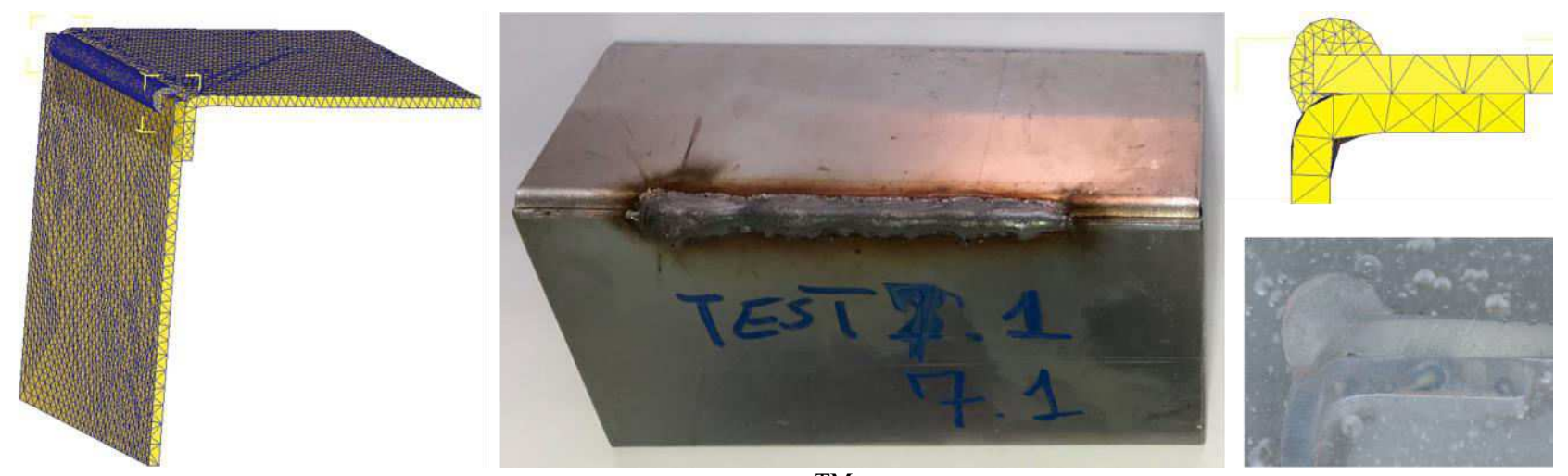

Fig. 12 Test 7: SFTC DEFORM-3D ${ }^{\mathrm{TM}}$ finite element modelling

Concerning the commercial FE software SFTC DEFORM-3D ${ }^{\mathrm{TM}}$, the two plates were modelled as a plastic body meshed with 50000 iso-parametric tetrahedral elements, while for the weld bead a plastic model with 32000 elements was considered (Fig. 12). In this case the Goldak's double-ellipsoid heat source was modelled by a series of 3D heat exchange windows (Fig. 13) with a movement velocity of $800 \mathrm{~mm} / \mathrm{min}$ as for the experimental welding speed. By the experimental weld bead geometry, cooling rate and HAZ were determined all the features characterizing the heat exchange windows: heat source parameters, convection coefficient and temperature.
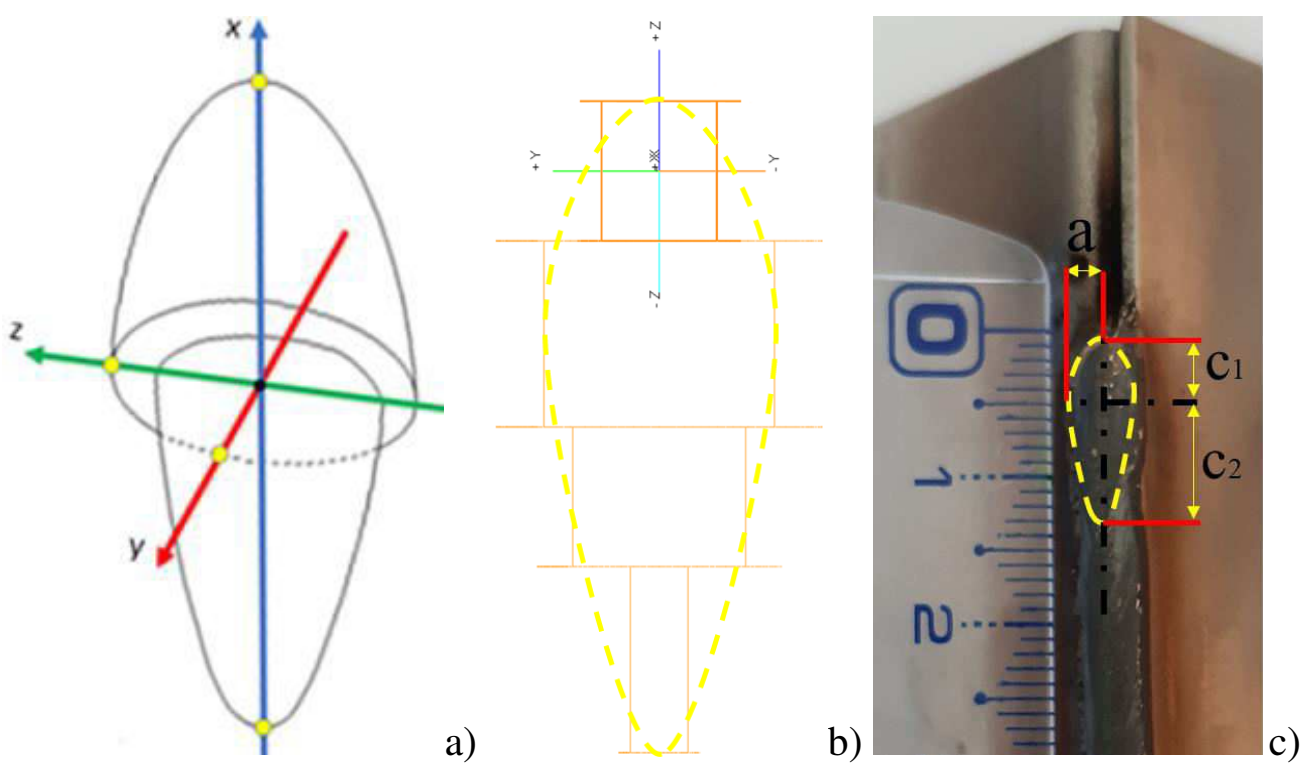

Fig. 13 Goldak's double-ellipsoid a), SFTC DEFORM- $3 \mathrm{D}^{\mathrm{TM}}$ heat source modelling b), measurement of the ellipsoidal heat source parameters $\mathrm{a}, \mathrm{c}_{1}$ and $\mathrm{c}_{2} \mathrm{c}$ )

In particular, the parameters $a, c_{1}$ and $c_{2}$ were measured on the welded plates (Fig. 13c), while the parameter $b$, the temperature and the convection coefficient of the heat exchange windows were calibrated by an iterative trial and error procedure of comparison between the numerical and experimental HAZ extension and the cooling profile (Fig. 14). 

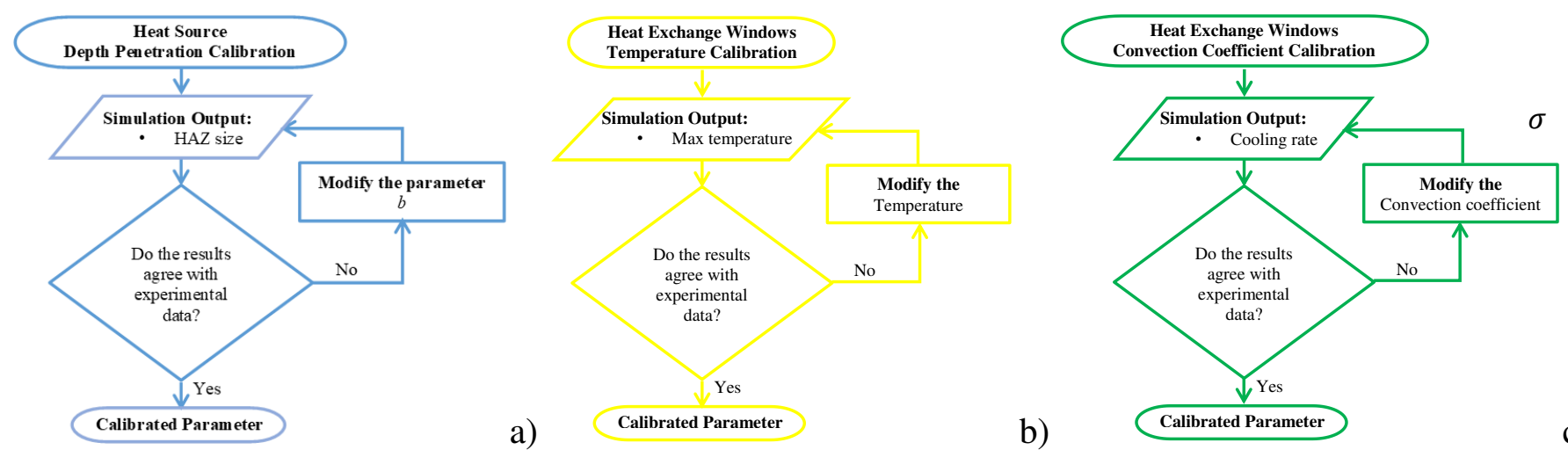

Fig. 14 Iterative procedure to calibrate the heat source depth penetration a), the temperature of the heat exchange window $b$ ), the convection coefficient of the heat exchange window $c$ )

The welding phenomena influencing the $\begin{array}{llll}240000 & 8.314 & 4 & 0.035\end{array}$ microstructure (i.e. grain size) of the HAZ were predicted by developing a customized user subroutine involving the classic kinetic theory for grain growth [19, 20], Eq. 2.

$$
D^{m}-D_{0}^{m}=t \cdot k
$$

Where $D$ is the current grain size, $D_{0}$ is the initial grain size, $m$ is the grain growth exponent, $k$ is the kinetic constant and $t$ is the soaking time. The grain growth kinetic constant $k$ can be expressed by Arrhenius form as function of the temperature, Eq. 3.

$$
k=k_{0} \exp \left(-\frac{Q}{R T}\right)
$$

Where $k_{0}$ is a pre-exponential constant, $Q$ is the activation energy for grain growth, $R$ is the gas constant and $T$ is the temperature. Combining Eq. 2 and Eq. 3 it is possible to define the expression for the grain growth kinetics as in Eq. 4.

$$
D=\sqrt[m]{t k_{0} \exp \left(-\frac{Q}{R T}\right)+D_{0}^{m}}
$$

The values of the numerical parameters of Eq. 4 are listed in Table 3.

Table 3 Parameters for the grain growth kinetics

\begin{tabular}{lllll}
\hline $\mathbf{Q}[\mathrm{J} / \mathrm{mol}]$ & $\mathbf{R}[\mathrm{J} / \mathrm{mol} * \mathbf{K}]$ & $\mathbf{m}$ & $\mathbf{D}_{\mathbf{0}}[\mathrm{mm}]$ \\
\hline
\end{tabular}

$[21] \quad[21] \quad[20] \quad$ Exp

For $t^{*} k_{0}$ it was considered a constant value, validated during simulations and set equal to $10^{5}$.

Finally, the hardness modification depending on the grain size evolution was calculated according to the H-P relation (Eq. 1). The value of $C_{0}$ and $C_{1}$ was determined, for each test, through the previously measured values of the material hardness and grain size of both HAZ and base metal, Table 4.

Table 4 Constants for H-P hardness model

\begin{tabular}{ccc}
\hline & $\boldsymbol{C}_{\boldsymbol{0}}$ & $\boldsymbol{C}_{\boldsymbol{1}}$ \\
\hline Test 0 & 165.36 & 15.46 \\
\hline Test 1 & 139.10 & 20.38 \\
\hline Test 3 & 180.28 & 12.67 \\
\hline Test 7 & 185.27 & 11.73 \\
\hline
\end{tabular}

Considering the average value of the four tests it was found 167.5 for $C_{0}$ and 15.1 for $C_{1}$ with an overall error less than $4 \%$ when recalculating the hardness for each single test.

\section{FE ANALYSIS AND RESULTS}

Completed the calibration and validation phase of the SYSWELD numerical model, it was used to analyse the effect of the investigated factors on residual stresses and strains and geometrical distortions. In Fig. 15 it is shown the variation of the 
residual stresses and strains of the four experiments (test $0,1,3$ and 7) that allowed to join the plates.
Each curve represents the average value of the three repetitions did per each test.
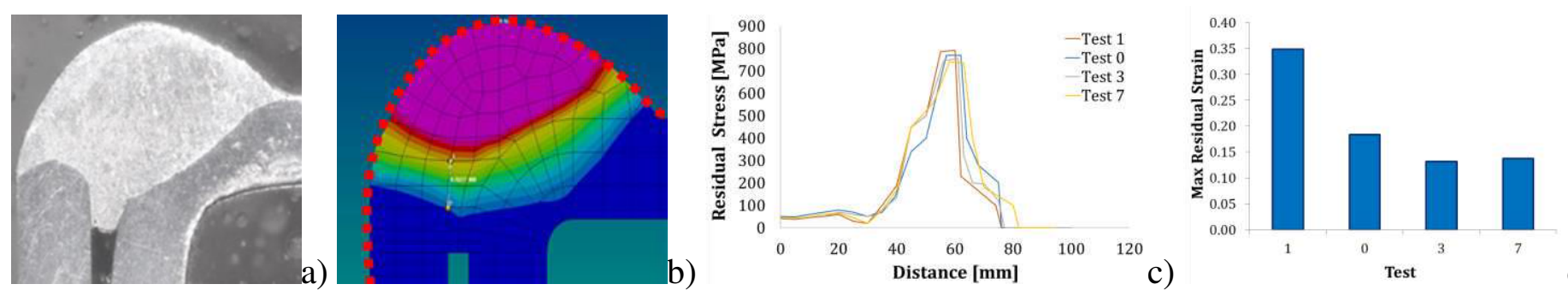

Fig. 15 Transverse section macrograph a) and SYSWELD analysed profile points b): test 0, numerical analysis of the residual stresses c) and maximum residual strains d)

Analysing the tests 1,0 and 3 , in which the overlap between the two welded plates increased from 8 to $10 \mathrm{~mm}$, it is evident a slight decreasing trend of the maximum peak of the residual stresses and strains. This is mainly due to the reduced temperatures (effects reported in Fig. 7) that result in a slow cooling rate leading to decreasing residual stresses and strains when higher overlaps were set. Also comparing test 1 and test 7 , in which the torch position was shifted on $\mathrm{x}$-axis, it was shown a residual stress and strain decrease for the reduced cooling rate noticed.
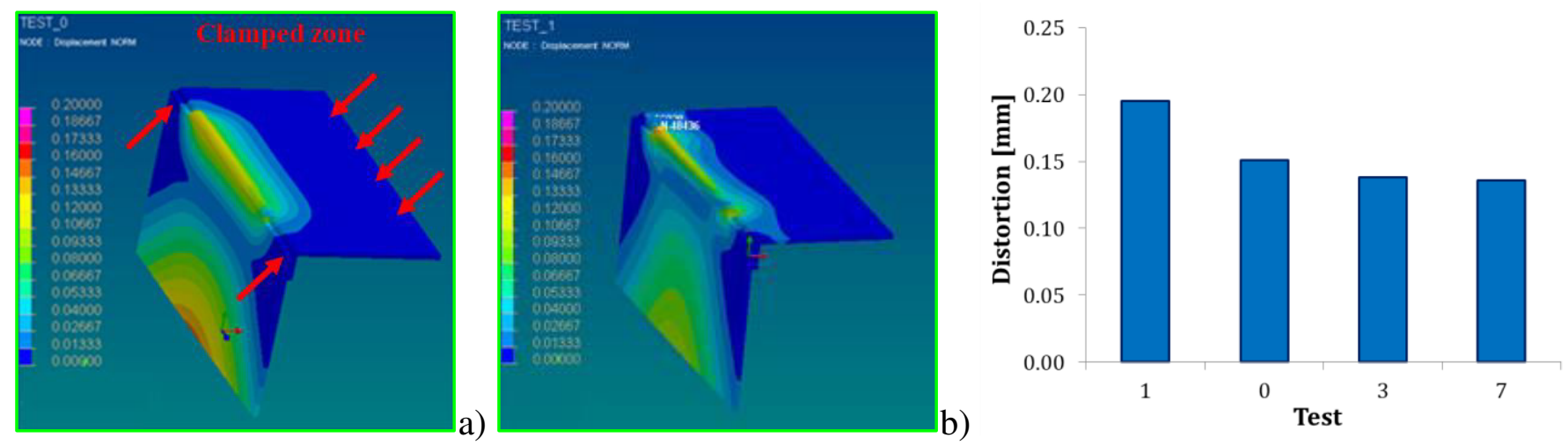

Fig. 16 Numerical analysis of distortions: entire welded surface of test 0 a) and test $1 \mathrm{~b}$ ), maximum value c)

In Fig. 16 it is reported the analysis related to the distortions of the welded plates. According with the experimental setup (Fig. 1), no displacements resulted in the clamped zone. Moreover, considering the components constrained only on one side, the final distortions were limited in a range of 0.10 and $0.25 \mathrm{~mm}$, following the same behaviour of the previously analysed residual strains. 

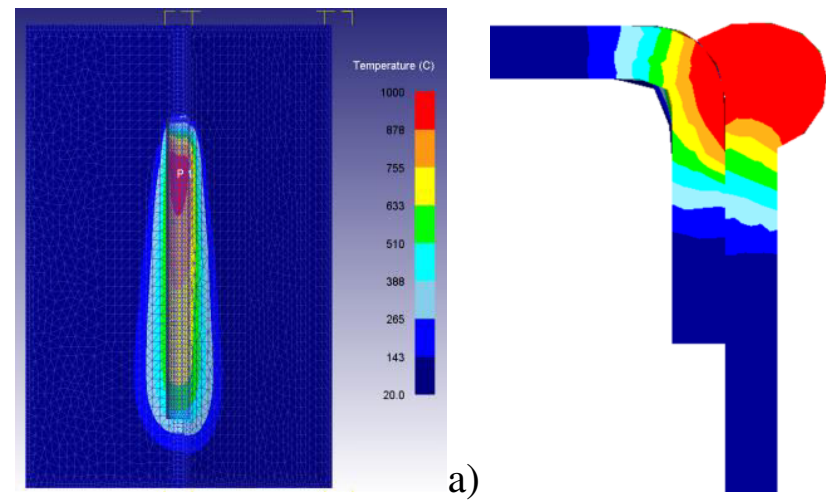
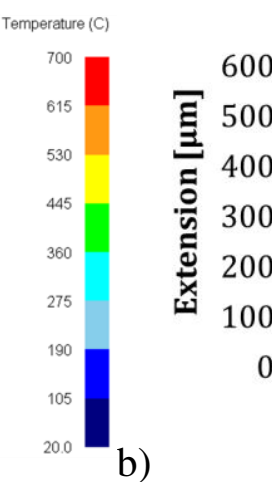

Heat Affected Zone

口Exp घNum

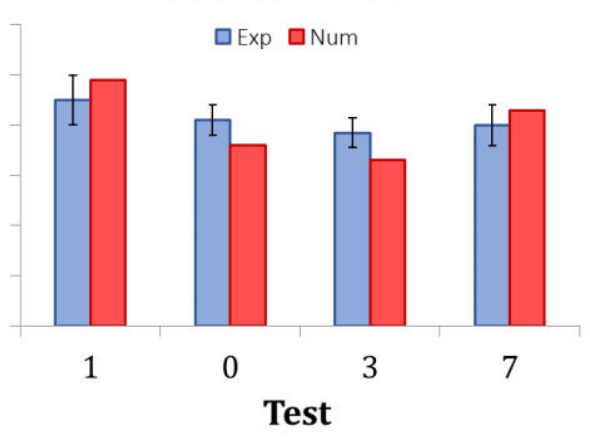

c)

Fig. 17 Numerical heat source moving a), test 7-predicted cross section temperature profile b), numerical analysis of the HAZ extension c)

Fig. 17a shows the numerical heat source, moving along the conjunction line of the two plates, with a stable temperature profile (Fig. 17b), while in Fig. 17c it is reported the comparison between the predicted HAZ extension and the corresponding experimental measurement. An overall average error of $10 \%$ was found (with a maximum of $14 \%$ when considering test 3) mainly due to both the numerical procedure (i.e. discretization, trial and error calibration procedure and number of numerical constants and equations) and experimental accuracy. Nevertheless, the contained deviation between the predicted and measured data proves the robustness of the developed numerical technique, validating the accuracy of the proposed method in SFTC DEFORM-3D ${ }^{\mathrm{TM}}$ for Goldak's heat source modelling by using heat exchange windows. Fig. 18 reports the predicted grain growth and hardness change in the HAZ, confirming the correctness of the worked-out FEM and user routine in predicting the thermal aspects of the GMAW process and the consequent microstructural (i.e. grain size) and mechanical (i.e. hardness) changes. In particular, Fig. 18a shows the stable and uniform cross section grain size prediction, representing a new microstructure featured by a coarser grain size, in the HAZ, for the reached temperatures during the process. According with experimental evidence, a decreasing hardness trend was observed in the HAZ (Fig. 18b) according with the H-P relation (Eq. 1) as a consequence of the grain growth.

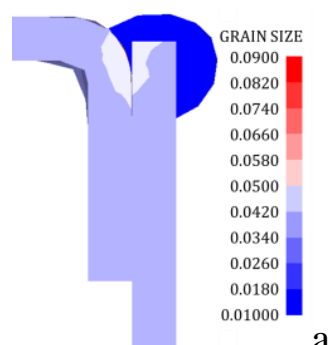

a)

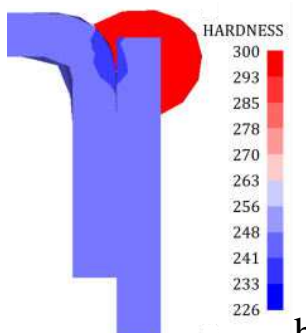

b)
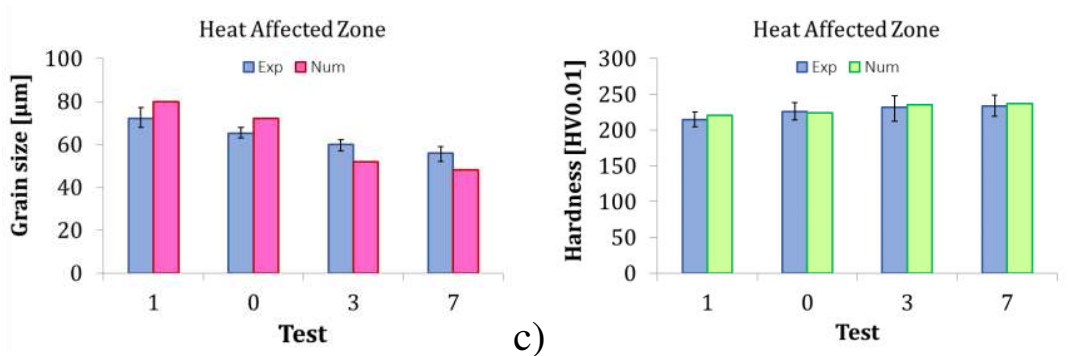

d)

Fig. 18 Test 7-predicted grain size $[\mathrm{mm}]$ a) and hardness variation $\left[\mathrm{HV}_{0.01}\right] \mathrm{b}$ ), comparison between experimental and numerical grain growth c) and hardness variation in the HAZ d)

In Fig. 18c is reported the comparison between numerical and experimental grain size variation in the HAZ: an overall average error of $11 \%$ was ascertained, with a maximum error of $14 \%$ when 
considering test 7 . While in Fig. $18 \mathrm{~d}$ is shown the measured and predicted comparison of the hardness change in the HAZ with an overall average error less than $7 \%$. The numerical results, validated with the corresponding experimental cases, demonstrate that, although the GMAW is characterized by a relative simplicity of execution, the weld region close to the welding line undergoes a complex thermal cycle for the localized heating and consequent cooling steps. Thus, a microstructural change occurs resulting in an average grain size increase in the HAZ and a consequent hardness decrease particularly detrimental for the in-safety performance of the products. Finally, the main influence of the thermal phenomena on the mechanical material properties and good quality of welding was proved.

\section{DISCUSSION AND CONCLUSIONS}

In this work two numerical models were developed to analyse the influence of some factors on the residual stresses and strains, the distortions, the grain growth and the hardness variation during GMAW process of AISI 441 plates. The commercial FE software SYSWELD was used for the numerical prediction of the residual stresses and strains and the distortions, while the commercial FE software SFTC DEFORM-3D ${ }^{\mathrm{TM}}$ was used for the numerical investigation of the grain size change and hardness evolution by developing two user sub-routines that implement the classic kinetic theory (i.e. grain growth) and the H-P equation (i.e. hardness decrease). Two software were implemented with the aim to have a wide knowledge of the several aspects characterizing the investigated process. The good agreement between the numerical and the experimental comparison of the HAZ extension validated the correctness of the modelled heat source parameters in SYSWELD and the robustness of the developed technique in SFTC DEFORM-3D ${ }^{\mathrm{TM}}$ to model the Goldak's double-ellipsoid heat source by heat exchange windows. Furthermore, the validation of the numerical results with the experimental evidences demonstrated the reliability of the two developed numerical models and user sub-routines in predicting the thermal phenomena that occur during GMAW process and the related metallurgical changes. Thus, the shown numerical procedure can be implemented for simulating the GMAW of AISI 441 steel plates, leading to analyse macro and microstructural aspects influencing the required quality outputs of the welded products. In this way, by the proposed approach, it is possible to predict, monitor and control the required microstructure and mechanical properties of the components and their final geometrical tolerances.

\section{DECLARATIONS}

Funding: Not applicable.

Conflicts of interest/Competing interests: The authors have no conflicts of interest to declare that are relevant to the content of this article.

Availability of data and material: Not applicable

Code availability: commercial FE software SYSWELD, commercial FE software SFTC DEFORM-3D ${ }^{\mathrm{TM}}$

Authors' contributions: Conceptualization, S.C. and D.U.; methodology, S.C. and D.U.; software, S.C.; validation, S.C.; formal analysis, D.U.; investigation, S.C. and D.U.; resources, S.C. and D.U.; data curation, S.C. and D.U.; writing - original draft preparation, S.C. and D.U.; writing-review and editing, S.C. and D.U.; visualization, D.U.; supervision, S.C. All authors have read and agreed to the published version of the manuscript.

Ethics approval: Not applicable.

Consent to partecipate: Not applicable.

Consent for publication: Not applicable.

\section{REFERENCES}


[1] Leonard M (2003) Laser Materials Processing, Laser Kinetics, Inc., California, pp 165-206

[2] Majumdar J D, Manna I (2003) Laser processing of materials, Sadhana, Vol. 28, pp 495-562

[3] Pervez Md R, Ahamed Md H, Ahmed Md A, Takrim S M, Dario P (2022) Autonomous grinding algorithms with future prospect towards SMART manufacturing: A comparative survey. J Manuf Syst 62:164-185. https://doi.org/10.1016/j.jmsy.2021.11.009

[4] Zawadzki P, Zywicki K (2016) Smart product design and production control for effective mass customization in the industry 4.0 concept. Manag Prod Eng Rev 7:105-112. https://doi.org/10.1515/mper-2016-0030

[5] Bu L, Zhang Y, Liu H, Yuan X, Guo J, Han S (2021) An IIoT-driven and AI-enabled framework for smart manufacturing system based on three-terminal collaborative platform. Adv Eng Inform 50:101370. https://doi.org/10.1016/j.aei.2021.101370

[6] Wippel M, Lucke D, Jooste J L (2021) An Industry 4.0 Technology Implementation Model for Rolling Stock Maintenance. Procedia CIRP 104:606-611.

https://doi.org/10.1016/j.procir.2021.11.102

[7] Angreani L S, Vijaya A, Wicaksono H (2020) Systematic Literature Review of Industry 4.0 Maturity Model for Manufacturing and Logistics Sectors. Procedia Manuf 52:337-343. https://doi.org/10.1016/j.promfg.2020.11.056

[8] Puliyaneth M, Chen H (2021) Study on the effect of welding residual stress on creep-cyclic plasticity behaviour. Int J Press Vessels Pip 193:104444.

https://doi.org/10.1016/j.ijpvp.2021.104444

[9] Woo D, Kitamura M, Takezawa A (2020) Systematic method for positioning clamps and strongbacks based on their influence on welding displacements. Ocean Eng 202:107084. https://doi.org/10.1016/j.oceaneng.2020.107084

[10] Unni A K, Vasudevan M (2021) Determination of heat source model for simulating full penetration laser welding of $316 \mathrm{LN}$ stainless steel by computational fluid dynamics. Mater Today: Proc 45:4465-4471. https://doi.org/10.1016/j.matpr.2020.12.842

[11] Dancette S, Huin T, Dupuy T, Fabregue D (2021) Finite element modeling of deformation and fracture of advanced high strength steels dissimilar spot welds. Eng Fract Mech 258:108092.

https://doi.org/10.1016/j.engfracmech.2021.108 $\underline{092}$

[12] Meyghani B (2021) A modified friction model and its application in finite-element analysis of friction stir welding process. J Manuf Process 2:29-47.

https://doi.org/10.1016/j.jmapro.2021.10.008

[13] Mondal A K, Kumar B, Bag S, Nirsanametla Y, Biswas P (2021) Development of avocado shape heat source model for finite element based heat transfer analysis of high-velocity arc welding process. Int J Therm Sci 166:107005. https://doi.org/10.1016/j.ijthermalsci.2021.1070 $\underline{05}$

[14] Heyraud H, Robert C, Mareau C, Bellett D, Morel F, Belhomme N, Dore O (2021) A twoscale finite element model for the fatigue design of large welded structures. Eng Fail Anal 124:105280.

https://doi.org/10.1016/j.engfailanal.2021.10528 $\underline{0}$

[15] Shen N, Samanta A, Cai W W, Rinker T, Carlson B, Ding H (2021) 3D finite element model of dynamic material behaviors for multilayer ultrasonic metal welding. J Manuf Process 62:302-312. https://doi.org/10.1016/j.jmapro.2020.12.039 
[16] Long D J, Devaney R J, O'Donoghue P E, Song H, Barrett R A, Leen S B (2021) Characterisation of LCF performance of X100 weld-joints: Mechanistic yield strength modelling, finite element analyses and DIC testing. J Adv Join Process 3:100057. https://doi.org/10.1016/j.jajp.2021.100057

[17] Wang C, Liu H, Chen Z, Zhao D, Wang C (2021) A new finite element model accounting for thermal contact conductance in laser transmission welding of thermoplastic. Infrared Phys Technol 112:103598. https://doi.org/10.1016/j.infrared.2020.103598

[18] Gunawardena Y, Aslani F (2021) Finite element modelling of concrete-filled spiral-welded stainless-steel tube columns under concentric and eccentric axial loading. Structures 33:11191143. https://doi.org/10.1016/j.istruc.2021.05.015

[19] Huang Y-C, Su C-H, Wu S-K, Lin C (2019) A Study on the Hall-Petch Relationship and Grain Growth Kinetics in FCC-Structured High/Medium Entropy Alloys. Entropy 21:297. https://doi.org/10.3390/e21030297

[20] Moravec J, Novakova I, Sobotka J, Neumann H (2019) Huang Y-C, Su C-H, Wu S-K, Lin C (2019) Determination of Grain Growth Kinetics and Assessment of Welding Effect on Properties of S700MC Steel in the HAZ of Welded Joints. Metals 9: 707. https://doi.org/10.3390/met 9060707

[21] Sello M P, Stumpf W E (2011) Laves phase precipitation and its transformation kinetics in the ferritic stainless steel type AISI 441. Mater Sci Eng A 528:1840-1847. https://doi.org/10.1016/j.msea.2010.09.090 